\title{
El cambio urbano en el Tercer Mundo. ¿Son las últimas tendencias un indicador útil del futuro urbano?
}

\author{
Jorge E. Hardoy* y David Satterthwaite**
}

\begin{abstract}
Ante las proyecciones de la población urbana para el año 2000 elaboradas por la Organización de las Naciones Unidas (ONU), así como su pronóstico acerca del crecimiento de las ciudades del Tercer Mundo, este artículo cuestiona la validez de los datos utilizados para pronosticar el cambio urbano en el Tercer Mundo. Posteriormente se analiza la posibilidad de de hacer generalizaciones válidas sobre el cambio urbano en el Tercer Mundo, en vista de la diversidad de estructuras económicas, tasas de crecimiento poblacional, niveles de ingreso per cápita y cantidad de población. Para ello se incluye un análisis por separado para América Lartina, Asia y África sobre algunos de los factores que influyen sobre los cambios urbanos entre 1960 y principios de 1980 . Con base en esa reseña se evalúa la validez de las proyecciones de la Naciones Unidas para los futuros niveles de urbanización por países o para las futuras poblaciones de ciertas ciudades del Tercer Mundo.
\end{abstract}

\section{Introducción}

Buena parte de lo que actualmente se escribe sobre los temas urbanos del Tercer Mundo se refiere al rápido (e incluso "explosivo") crecimiento de las ciudades. Las publicaciones de Naciones Unidas nos recuerdan que aproximadamente la mitad de la población mundial será "urbana" en el año 2000, y muchos autores han interpretado esto como que la mitad de la población dél mundo vivirá en "ciudades" en el año 2000. Las proyecciones de las Naciones Unidas pronostican que en menos de cuarenta años habrá $\mathbf{5 0 0}$ ciudades con un millón de habitantes o más en el Tercer Mundo, comparadas con las 119 que existían en 1980 (Naciones Unidas, 1985). También pronostica Naciones Unidas que la cantidad de ciudades del Tercer Mundo con 4 millones de habitantes o más se multiplicará varias veces, de 22 en 1980 a 114 en el año 2025 (Naciones Unidas, 1985). Por lo tanto, no debería sorprender a nadie que se acepte que todas las ciudades del Tercer Mundo crezcan rápidamente y de que es probable que las tendencias urbanas de las últimas décadas continúen y, de esa manera, nos brinden datos confiables para proyectar en el futuro. Sin embargo, un análisis de recientes datos censales y de las fuerzas y factores que estimularon el

\footnotetext{
* Director de la Oficina Latinoamericana del IIED, con sede en Buenos Aires.

** Investigador de la Oficina Latinoamericana del IIED, con sede en Londres.
} 
cambio urbano en diferentes países del Tercer Mundo nos lleva a dudar seriamente de la validez de estos supuestos.

Este documento tiene tres objetivos. El primero es el de estudiar la validez de los datos en los que se basaron las estadísticas utilizadas para pronosticar el cambio urbano en el Tercer Mundo. El segundo es el de analizar si pueden hacerse generalizaciones válidas sobre el cambio urbano en el Tercer Mundo, y el tercero, es el de estudiar la validez de las proyecciones de las Naciones Unidas para el futuro del Tercer Mundo.

\author{
¿Qué validez tienen las estadísticas utilizadas para \\ comparaciones urbanas internacionales?
}

Todavía es corriente comparar los niveles de urbanización entre diferentes países, es decir, el porcentaje de la población de un país que vive en "centros urbanos". Para hacer estas comparaciones se utilizan normalmente las cifras de publicaciones de Naciones Unidas o de los cuadros del World Development Report, publicado anualmente por el Banco Mundial, cuyas estadísticas se basan, en gran mayoría, en las cifras proporcionadas por Naciones Unidas. Estas cifras se utilizan para demostrar que determinado país o región está "más urbanizado que otro". Estas comparaciones continúan realizándose a pesar de que las notas al pie de página, incluidas en los cuadros que presentan los diferentes niveles de urbanización de los países, generalmente aclaran que cualquier comparación entre países debe "interpretarse con precaución" debido a las diferentes definiciones de lo que es "urbano". De ahí que se califique a la India como un país predominantemente rural porque, de acuerdo con el censo de 1981, $24 \%$ de su población vivía en "áreas urbanas". Perú, por el contrario, está calificado como medianamente urbanizado ya que, según las cifras de Naciones Unidas, $67 \%$ de su población vivía en áreas urbanas en 1985 . Pero en Perú se definen como "centros urbanos" a los centros con 100 o más viviendas ocupadas, mientras que en la India los criterios utilizados son más complicados. Salvo raras excepciones, los centros urbanos de la India tienen 5000 habitantes o más, una densidad relativamente alta y más de tres cuartos de la población masculina adulta está dedicada a tareas agrícolas. Gran parte de la población rural de la India vive en pueblos con más de 100 viviendas ocupadas. Por lo tanto, si el gobierno de la India decidiera cambiar el criterio para determinar su "población urbana" utilizando el del gobierno peruano, la India, de pronto, se transformaría en el país más urbanizado de Asia. Esto, a su vez, modificaría radicalmente las estadísticas sobre el nivel de urbanización del sur de Asia e incluso, y de modo 
significativo, los niveles de urbanización del Tercer Mundo y del resto del mundo. De igual manera, el modo como se determina la población urbana de China puede modificar radicalmente la cantidad de población urbana del Tercer Mundo. Un reciente estudio sobre la urbanización en China (Kirkby, 1985) incluyó un capítulo entero dedicado al análisis de la mejor manera de determinar la población urbana de ese país. Según cuál de los dos criterios más comúnmente utilizados se aplique para China, 13.9 o $20.2 \%$ de su población en 1981 era urbana. Puesto que la elección de uno u otro porcentaje significa la inclusión o exclusión de unos 60 millones de habitantes, la diferencia no es nada despreciable. Más aún, si el criterio del gobierno peruano para determinar la población urbana se aplicara en China, las cifras de los niveles de urbanización en China y Asia, así como también en el resto del mundo, se verían radicalmente modificadas.

En la mayoría de los países más poblados del Tercer Mundo son definidos como centros urbanos aquellos asentamientos que superan un número de habitantes establecido. Pero este umbral puede ser de unos centenares de habitantes o de más de 50000 habitantes. En general, el umbral adoptado oscila entre los 1500 y 5000 habitantes. Para determinar la "población urbana de un país" se utilizan corrientemente otros dos tipos de criterios que no están basados en umbrales poblacionales. El primero de ellos es, sencillamente, cuando se declara que ciertos asentamientos deben ser considerados "centros urbanos". Este criterio, utilizado frecuentemente en países con escasa población y relativamente poco urbanizados, designa a unos cuantos asentamientos como "centros urbanos". En algunos de los países de menor población, a veces un solo asentamiento es considerado urbano. El segundo ćriterio se basa en la población de un asentamiento en el que se concentran funciones administrativas de gobierno: un asentamiento es "urbano" si es la sede de un gobierno local de cierta jerarquía. En algunos países existe una relación jerárquica entre el nivel del gobierno local y el número de habitantes; de esta manera, un asentamiento es urbano si su población excede un umbral establecido y si es sede de un gobierno local con cierta jerarquía. A estos criterios de umbrales de población y de jerarquía del gobierno local se agregan otros más complejos, como son el porcentaje de la mano de obra dedicada a actividades no agrícolas, o la densidad de población u otras características consideradas como típicas de un "centro urbano". Además, en algunos países, se define como "población urbana" a aquellas personas que viven agrupadas en uno o más asentamientos con características definidas como "urbanas" dentro de los límites de municipios o de otros tipos de áreas administrativas. Podría ser interesante investigar cómo diversos países del Tercer Mundo llegaron a establecer los criterios urbanos que utilizan actualmente por ejemplo, el criterio urbano en diversas ex colonias francesas es similar al utilizado por sus antiguos gobernantes. Pero es éste un tema que escapa a los objetivos del presente trabajo. 
La gran diversidad de métodos que utilizan los gobiernos nacionales para definir los niveles de urbanización reduce, en gran medida, la validez de las comparaciones internacionales. Esto se verá claramente con algunos ejemplos. De la población de Bolivia, $32.2 \%$ hubiera sido urbana en 1976 si se adoptaba el umbral de 20000 habitantes para definir a un asentamiento como "urbano", o $42.6 \%$ si el umbral hubiera sido de 2000 habitantes. ${ }^{1}$ De la población de México, $43.3 \%$ habría sido definida como urbana en 1970 si se hubiese adoptado el umbral de 20000 habitantes o más y $59 \%$ adoptando como criterio el de localidades con 2500 habitantes o más. ${ }^{2}$ Si los centros urbanos del Perú fueran sólo aquéllos con 50000 habitantes o más, el nivel de urbanización en 1981 hubiera sido de 44\% de la población nacional y no alrededor de 67 por ciento. ${ }^{3}$

Las estadísticas publicadas por Naciones Unidas con el número de habitantes que vive en ciudades de 100000 habitantes o más en todos los países del mundo, constituyen la base más sólida para realizar comparaciones internacionales, pues utilizan el mismo criterio para todos los países. Pero, aun en ese caso, se sabe que las estadísticas de ciertos países son inexactas. Muchos países no han realizado censos de población en los últimos años. Por lo tanto, las cifras poblacionales para las ciudades de más de 100000 habitantes que publica Naciones Unidas se obtienen por la extrapolación de datos antiguos. Aparentemente, estas extrapolaciones no tomaron en cuenta a las ciudades que probablemente pasaron a la categoría de las de más de $\mathbf{1 0 0} \mathbf{0 0 0}$ habitantes entre el último censo y los últimos años. De esta manera, de acuerdo con un reciente compendio de estadísticas urbanas de Naciones Unidas, China tenía una sola ciudad con una población de entre 100000 y 249999 habitantes en $1980(\mathrm{Na}$ ciones Unidas, 1985). Esto es poco creíble para un país de más de 1000 millones de habitantes y, cualquiera que haya sido el criterio utilizado para calcularla, con una de las poblaciones urbanas más numerosas del mundo.

Naciones Unidas es reacia a utilizar cifras estimadas por investigadores locales en aquellos países que carecen de censos actualizados. Por ejemplo, la cifra publicada por Naciones Unidas en 1985 para la población de Lagos en $1980-2.8$ millones de habitantes-(Naciones Unidas, 1985) es más realista que la de 1.17 millones en ese mismo año, publicada en 1980 (Naciones Unidas, 1980). Sin embargo, desde hace bastante tiempo, los investigadores locales señalaron que el conglomerado urbano de

\footnotetext{
${ }^{1}$ Extraido del censo de 1976 citado en: Naciones Unidas, Policies on human settlements in Bolivia, UNCHS, Nairobi, 1977.

${ }^{2}$ Extraído de cifras censales citadas en Beatriz Cuenya, Rubén Gazzoli y Óscar Yujnovsky, Evaluación de las recomendaciones de Vancouver para una acción nacional, Ediciones CEUR, Buenos Aires, 1978.

${ }^{3}$ Extraído de las cifras censales citadas en H. W. Richardson, "Planning strategies and policies for Metropolitan Lima". Third World Planning Review, vol, 6, núm. 2, mayo, 1984.
} 
Lagos tenía en 1980 entre cuatro y cinco millones de habitantes (véase Aradeon, Aina y Umo, 1986). Sin duda, al gobierno de Nigeria le convenía anunciar cifras bajas para la población de Lagos, pues la cantidad de habitantes es uno de los criterios en los que se basa la distribución de los recursos federales. Las cifras presentadas por Naciones Unidas para Lagos fueron tan bajas que alguien comentó que Nigeria, comparada con cualquier otro país del Tercer Mundo, tiene el sistema urbano con el menor índice de primacía (Rondinelli, 1982), aunque debido a la concentración de la industria, los servicios y el comercio nacionales, Lagos sea una ciudad primada. Las cifras de Naciones Unidas sobre los niveles de urbanización de Nigeria también parecen ser bastante bajas. Quizá se basen únicamente, en extrapolaciones de la población de los centros urbanos existentes en 1963, fecha del último censo. Pero si estas estimaciones son demasiado bajas, pues casi no se considera a los asentamientos que crecieron y se desarrollaron como "centros urbanos" desde el último censo, quiere decir que las estadísticas de los niveles de urbanización de África Occidental son también demasiado bajas, teniendo en cuenta que Nigeria domina demográficamente a esta región.

Asimismo, pareciera existir un intervalo de tiempo considerable entre el momento en que se pudo disponer de las cifras de los censos nacionales y su utilización en las estadísticas de Naciones Unidas. Por ejemplo, los porcentajes de la población urbana en ciudades de más de 500000 habitantes en Kenia (57\%) y Tanzania (50\%) en 1980 , son bastante más altos que los que surgen del análisis de los censos de 1979 en Kenia y de 1978 en Tanzania. Esos porcentajes de Naciones Unidas eran todavía citados a fines de 1985 en los cuadros del World Development Report publicado por el Banco Mundial en ese año. Si se utilizan las cifras censales de esos países, el porcentaje de la población urbana en ciudades de 500000 habitantes o más en 1980 será mucho menor: en ambos países el porcentaje sería del orden de $35 \%$. Es posible que el porcentaje de la población urbana concentrada en ciudades de 500000 habitantes o más haya sido también exagerado para muchos otros países. Pero entonces, el porcentaje de la población urbana concentrada en ciudades de 500000 habitantes o más sería, también, erróneo debido a la diferencia de criterios que se utilizan para calcular la población urbana nacional.

Un último ejemplo de las estadísticas urbanas de Naciones Unidas que parecieran cuestionables son las cifras estimadas para los porcentajes de población que vive en ciudades de 100000 habitantes o más, en muchos países o regiones pequeñas. Entre $95 \%$ y $100 \%$ de la población urbana de muchos países del Tercer Mundo con poca población se dice que vivía en ciudades de más de 100000 habitantes en 1950, 1955 y 1960 (Naciones Unidas, 1985). Sin embargo, en Burundi, Djibouti, Santo Tomé y Príncipe, Gambia, Antigua, las Seychelles, Gibraltar, Nueva Caledonia, las islas Cook, Niue y las islas Faeroe, no existen ciudades que lleguen a los 100000 
habitantes. En realidad, las poblaciones nacionales de muchos de estos países o territorios no llegan a los 100000 habitantes, y en otros todavía no existe un centro urbano de 100000 habitantes.

¿Qué generalizaciones válidas pueden hacerse para los procesos de urbanización en los países del Tercer Mundo?

Aun cuando los niveles de urbanización de diferentes países o regiones del Tercer Mundo pudieran calcularse utilizando los mismos criterios, la utilidad de tales comparaciones sería limitada, salvo que formaran parte de un análisis más detallado de las fuerzas y factores que impulsan el cambio urbano en dos países o regiones diferentes. No puede afirmarse que dos centros urbanos con un número semejante de habitantes y tasas similares de crecimiento poblacional experimenten cambios económicos parecidos. Por ejemplo, el crecimiento vegetativo y la migración neța pueden contribuir al aumento de la población de un centro urbano de manera muy diferente. $\mathrm{O}$ también puede suceder que alguno de estos centros urbanos sufra un rápido aumento poblacional debido a la llegada de refugiados o de migrantes del área rural inmediata debido a una sequía, mientras que el crecimiento poblacional de otros centros puede deberse, en gran medida, a la migración de gente atraída por una expansión del comercio y los servicios que, a su vez, se desarrollaron por un rápido aumento de la producción agrícola en las áreas vecinas. Los movimientos poblacionales (y el crecimiento poblacional) originados por guerras y desastres naturales deben considerarse como casos especiales, pues estos movimientos pueden resultar temporarios. Sin embargo, pareciera que la influencia que tales "desastres naturales" ejercen sobre los movimientos poblacionales va en aumento y que su impacto se agrava, en gran medida, por la acción o falta de acción de los seres humanos. También, en diversos casos, muchos movimientos poblacionales impulsados por desastres naturales se convierten en dezplazamientos permanentes.

Como es posible hacer ciertas generalizaciones sobre las tendencias urbanas del mundo desarrollado en décadas recientes, al haber sufrido esos países transformaciones económicas y demográficas similares (aunque en décadas diferentes), se ha supuesto que generalizaciones similares pueden realizarse para el Tercer Mundo. Sin embargo, es más difícil señalar las "diversas" tendencias que existen en el Tercer Mundo que las del mundo desarrollado. Entre los países del Tercer Mundo existe una mayor diversidad en cuanto a estructuras económicas, tasas de crecimiento poblacional, niveles de ingreso per cápita y cantidad de población. Hay países con grandes recursos $u$ otros con muy escasos recursos. Las diferencias que existen entre los países más ricos e industrializados del Tercer Mundo, 


\section{CUADRO 1 Primacía de las ciudades dentro de las economías nacionales}

Abidjón (Costa de Marfil). Se dice que alrededor de $70 \%$ de todas las transacciones económicas y comerciales realizadas en 1978 en Costa de Marfil tuvieron lugar en Abidján, que contaba con $15 \%$ de la población nacional.

Bangkok (Tailandia). A principios de la década de 1970 en el área metropolitana se concentraba $\mathbf{8 6} \%$ del PIB generado por la banca, los seguros y el sector público inmobiliario, $74 \%$ de la industria, 61\% del gasto público destinado a la administración pública y a la defensa, y un tercio del Producto Interno Bruto (PIB). En esos años en Bangkok se concentraba $10 \%$ de la población nacional.

Lagos (Nigeria). En 1981, por el área metropolitana se embarcaba más de $40 \%$ del comercio exterior del país, y concentraba más de $57 \%$ del total del valor agregado de la industria y alojaba a más de $40 \%$ de la mano de obra altamente especializada. Lagos tenía $5 \%$ de la población nacional.

Lima (Perú). En el área metropolitana se concentraba 43\% del Producto Interno Bruto (PIB) en 1981 , cuatro quintas partes del crédito bancario y de la producción de bienes de consumo y más de $90 \%$ de la producción de bienes de capital del Perú. En ese año Lima tenfa $27 \%$ de la población nacional.

Managua (Nicaragua). Un informe de 1983 informaba que las empresas localizadas en Managua concentraban $38 \%$ del Producto Interno Bruto (PIB) nacional. En Managua se concentraba aproximadamente $27 \%$ de la población nacional

Manila (F̄ilipinas). El área metropolitana producía en 1981 un tercio del Producto Interno Bruto (PIB), manejaba $70 \%$ de todas las importaciones y concentraba $60 \%$ de todos los establecimientos fabriles. En ese año alojaba alrededor de $13 \%$ de la población nacional.

Ciudad de México (México). En 1970 tenfa 30\% del total de la mano de obra manufacturera, $28 \%$ de los empleados de comercio, $38 \%$ de los empleados en servicios, $68 \%$ de los empleados públicos, $62 \%$ de la inversión nacional en educación superior y $80 \%$ de la investigación. En 1965 concentraba $44 \%$ de los dépositos bancarios y $61 \%$ del crédito del país. En 1970 se concentraba en el área metropolitana alrededor de $24 \%$ de la población nacional.

Nairobi (Kenia). En 1975 concentraba 57\% de la mano de obra manufacturera del país y, en 1974, $67 \%$ de las plantas industriales. En 1979 Nairobi concentraba 5\% de la población nacional.

Puerto Príncipe (Haiti). Alrededor de $\mathbf{4 0 \%}$ del ingreso nacional se produce en Puerto Principe. Monopoliza virtualmente todas las actividades económicas urbanas. A esto contribuyó un sistema polftico y administrativo muy centralizado y las políticas de desarrollo industrial. All vive sólo $14 \%$ de la población del país.

Rangoon (Birmania). Está ubicado en el centro de la red de transportes y comunicaciones del pafs. Rangoon es el centro económico, político y administrativo de Birmania y de las actividades terciarias. Casi todo el comercio de importación y exportación del país pasa por su puerto. Se dice que más de la mitad de la industria manufacturera nacional está localizada allí. En 1981 tenía $6 \%$ de la población nacional.

São Paulo (Brasil). En 1980, São Paulo contribuyó con más de $40 \%$ del valor agregado industrial de Brasil y con un cuarto del producto nacional neto. En ese mismo año alojaba una décima parte de la población nacional.

Fuente: Hardoy, Jorge E. y David Satterthwaite, "Government policies and small and intermedíate urban centres", en Smol and intermediate urban centres. Their role in regional and national development in the Third World, J. E. Hardoy y D. Satterthwaite (editores); cuadro 2, pp. 335-397, Hodder and Stoughton, Londres, 1986.

No se incluye el porcentaje de la población urbana nacional que representa cada una de estas ciudades, pues los diferentes criterios utilizados por cada país para determinar qué es un centro urbano (y, por lo tanto, tener los parámetros para calcular la población urbana nacional) les restan validez para realizar comparaciones internacionales. 
como Brasil o Corea del Sur, y los más pobres, como Chad, Mali o Nepal, dificultan cualquier generalización sobre las perspectivas futuras del desarrollo urbano, al comparar aquellos países con pocas posibilidades de desarrollar economías viables y estables, con otros que se han transformado en potencias económicas dentro del mercado mundial.

Sin embargo, si intentamos entender mejor los procesos urbanos del Tercer Mundo y la especial y sumamente complicada mezcla de factores locales, regionales, nacionales e internacionales que influyen sobre los movimientos poblacionales dentro de cada país y de cada región, resulta útil tratar de hacer algunas generalizaciones. Pareciera que existen cuatro generalizaciones válidas sobre los procesos urbanos del Tercer Mundo durante las últimas décadas. La primera de ellas es que la mayoría de estos países experimentaron un crecimiento mucho mayor de la población urbana que de la rural, lo que significa que un porcentaje creciente de su población nacional vive en centros urbanos. La segunda es que en la mayoría de estos países se ha producido una creciente concentración de la población y de las actividades económicas en una o dos ciudades, áreas metropolitanas o "regiones nucleares". El cuadro 1 da algunos ejemplos de ciudades con una alta concentración de la producción y comercio nacionales. La tercera es que el rápido crecimiento de la población urbana y rural ha sido simultáneo; sólo desde hace relativamente poco tiempo la población rural comenzó a disminuir en algunos países del Tercer Mundo, pero en la mayoría de ellos parecería que en un futuro próximo la población rural continuará creciendo rápidamente. La cuarta es que, en conjunto, el crúimiento vegetativo ha contribuido históricamente más al crecimiento de la población urbana que la migración neta del campo a la ciudad. Sin embargo, respecto a este último punto, según lo demuestran los ejemplos que daremos más adelante, en muchas ciudades de diversos países la migración neta del campo a la ciudad ha contribuido más que el crecimiento vegetativo en las últimas décadas. También, en muchos casos, un gran porcentaje de la migración hacia las ciudades es de jóvenes, que en poco tiempo tendrán hijos, mientras que muchos de los que migran de la ciudad al campo son gente relativamente mayor en edades no fértiles. De modo que un gran porcentaje del crecimiento urbano de una ciudad se debe, en gran medida, a la rápida inmigración de gente joven en años anteriores.

A pesar de que, como se sugirió anteriormente, se plantean serias dudas en cuanto a la validez de las comparaciones internacionales sobre niveles de urbanización, nos enfrentamos con el problema de que no hay otras fuentes de información alternativas que cubran el Tercer Mundo. Algunos censos recientes incluyen suficiente información sobre el porcentaje de la población de cada país en asentamientos con rangos demográficos bien definidos, pero el número de censos es demasiado reducido como para intentar una alternativa lo suficientemente general, con cifras basa- 
das en los criterios utilizados en cada país. Las estadísticas de Naciones Unidas para el porcentaje de poblaciones nacionales en ciudades de 100000 habitantes o más, parecen ser una base más firme para hacer comparaciones internacionales, a pesar de las reservas expresadas anteriormente.

Para aclarar algunos aspectos del cambio urbano entre 1960 y principios de 1980 hemos incluido secciones separadas para América Latina, Asia y África. Evitamos, siempre que fue posible, realizar comparaciones entre los diferentes niveles de urbanización de los países con cifras proporcionadas por Naciones Unidas, por las razones antes mencionadas. Sin embargo, no existe otra fuente de información que la proporcionada por Naciones Unidas sobre los cambios en los niveles de urbanización a lo largo del tiempo. Por lo tanto, comentamos la magnitud del cambio en los porcentajes de la población de diferentes países que vive en "centros urbanos" desde 1960, pues esto nos da una cuantificación del alcance de la concentración de las poblaciones nacionales en asentamientos con algunas características urbanas. También tratamos de vincular las tendencias urbanas con las fuerzas y factores que promueven esas tendencias.

\section{América Latina}

Según indicamos en el cuadro 2, la proporción de la población de las diversas regiones de América Latina asentada en 1980 en ciudades de más de 100000 habitantes y de más de 1 millón de habitantes, era la más alta entre todas las regiones del Tercer Mundo. En realidad, el cono sur de Sudamérica tenía, tanto en 1960 como en 1980, un mayor porcentaje de su población asentada en ciudades con los rangos indicados de las regiones desarrolladas del mundo. Hacia 1985, cuatro áreas metropolitanas (ciudad de México, São Paulo, Rio de Janeiro y Buenos Aires) tenían más de 10 millones de habitantes y figuraban entre los 15 conglomerados urbanos más populosos del mundo.

Los países con más rápido crecimiento económico e industrial durante las décadas de 1960 y de 1970, tales como México, Colombia y Brasil, tendían también a ser los países con mayor incremento de la población en centros urbanos. Entre 1960 y 1982, el porcentaje de la población urbana creció de 51 a $68 \%$ en México, de 45 a $69 \%$ en Brasil y de 48 a $65 \%$ en Colombia.

Tres países del cono sur - Chile, Uruguay y Argentina- tuvieron un crecimiento urbano más lento y niveles de urbanización menos dramáticos. En Argentina, el porcentaje de la población nacional en áreas urbanas creció solamente de 74 a $83 \%$ en esos 22 años, mientras que el de Uruguay lo hizo de 80 a $84 \%$. Sin embargo, estos tres países no sólo están entre los más urbanizados de América Latina y del mundo. Estos países tuvieron, durante las décadas de 1960 y 1970, el más lento crecimiento de su 


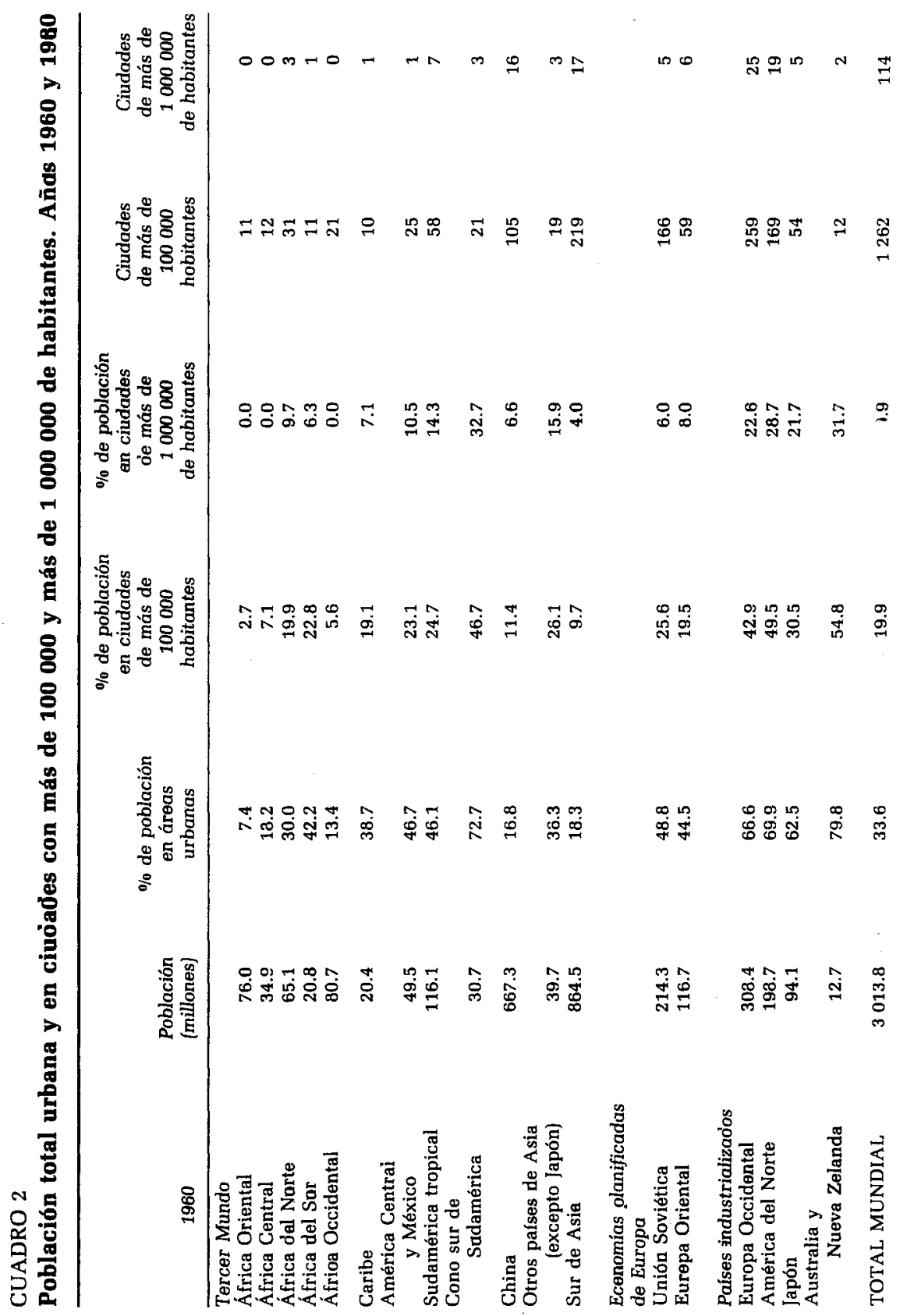




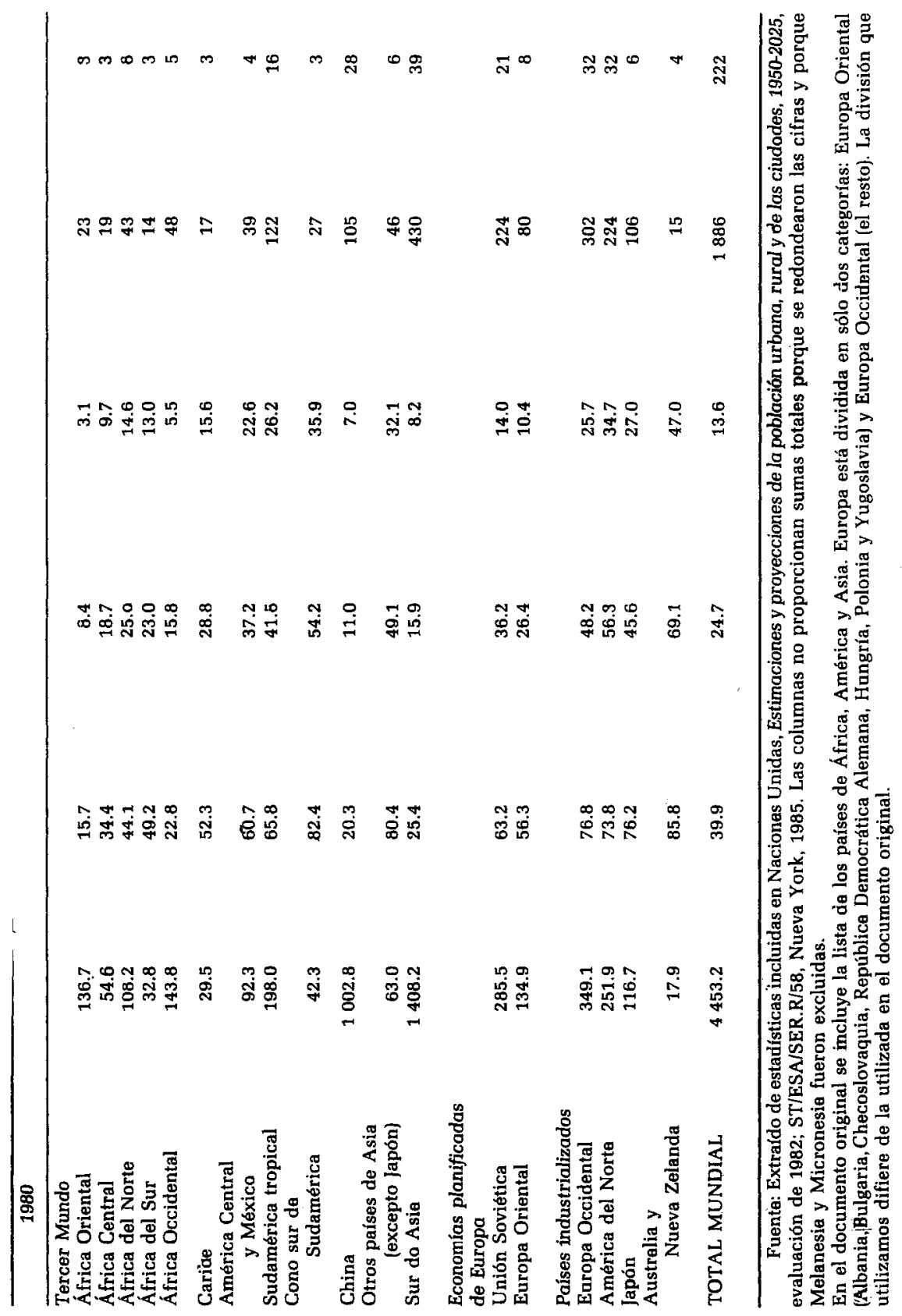


producción industrial de América Latina; más aún, Argentina y Chile sufrieron una disminución en su fuerza laboral ocupada en la industria. En 1980 , aproximadamente $36 \%$ de sus poblaciones nacionales vivía en ciudades con más de un millón de habitantes, lo que representaba un porcentaje mayor que el de Japón, América del Norte o Europa Occidental. La explicación se encuentra en la historia económica y demográfica de estos países. Argentina y Uruguay, por ejemplo, y también el sur de Brasil, recibieron importantes volúmenes de inmigrantes provenientes de Europa a fines del siglo XIX y comienzos del XX, periodo en el que no se registró ningún cambio importante en la tenencia de la tierra rural. Los latifundios y las escasas redes de transporte impidieron a los inmigrantes dedicarse a tareas rurales. Las únicas excepciones fueron algunas zonas donde se implementaron programas oficiales de colonización, aunque las colonias agrícolas sólo afectaron un pequeño porcentaje de las mejores tierras agrícolas. Debemos recordar que para los inmigrantes europeos era más fácil, económico y rápido llegar a la costa oriental de América del Sur, antes que a los países andinos. Así fue que en la zona de esta costa se concentró la inversión de capitales, la mayoría provenientes del extranjero. El desarrollo urbano fue estimulado por inversiones en la industria y en infraestructura, como son ferrocarriles, servicios urbanos y puertos; la mayor parte de estas inversiones estaría destinada a servir a los intereses económicos nacionales e internacionales radicados en las ciudades más populosas. Buenos Aires y Rosario en Argentina, Montevideo en Uruguay, y São Paulo y Rio de Janeiro en Brasil, experimentaron un mayor crecimiento poblacional a fines del siglo XIX y comienzos del xx que en décadas posteriores.

Las estadísticas de las últimas cuatro décadas indican que hubo una mayor concentración de las actividades productivas y de la población urbana en sólo una o dos ciudades, áreas metropolitanas o "regiones nucleares" en la mayoría de los países de América Latina, si bien, como mencionamos, en varios países este proceso comenzó hace muchas décadas. Un elevado porcentaje de la industria latinoamericana se concentra en unas pocas regiones nucleares. Tres de las más prominentes son: La Plata-Buenos Aires-Zárate-San Nicolás- Rosario-San Lorenzo, en Argentina; el triángulo Rio de Janeiro-São Paulo-Belo Horizonte, en Brasil, y ciudad de MéxicoToluca-Cuernavaca-Puebla-Querétaro, en México. Mientras que la tendencia general en América Latina había sido hacia una mayor concentración de las nuevas industrias en las grandes ciudades, o de las industrias en expansión dentro de los límites o cerca del área central de las ciudades principales, en años recientes el empleo industrial y comercial creció más rápidamente fuera de las ciudades centrales. Existen numerosos ejemplos de un crecimiento menor, y hasta de pérdida de población, de las ciudades centrales con respecto a sus suburbios y a las ciudades que están fuera del área de influencia inmediata de las áreas metropolitanas, así como de grandes centros urbanos con una tasa de crecimiento poblacional mayor 
que el de áreas metropolitanas. A este proceso se le denomina antipolarización (véase Townroe y Keen, 1984: 45-54, para un análisis sobre la mejor forma de cuantificarlo). Por ejemplo, en Buenos Aires, el distrito central (la capital federal) perdió población entre 1970 y 1980, mientras que la población de los "partidos" provinciales que forman parte del área metropolitana de Buenos Aires, pero fuera del distrito capitalino, tuvo un aumento de 30\% (Rofman, 1985). Quizás, a largo plazo, sea más significativo el hecho de que el Gran Buenos Aires, dentro del porcentaje que le correspondió con respecto a la población nacional, tuvo un aumento de sólo $0.1 \%$ durante la década de 1970 , comparado con $2 \%$ de aumento durante la década de $1960{ }^{4}$

A partir de 1940, la población del Gran São Paulo creció con mayor rapidez que la de la ciudad de São Paulo. Entre 1940 y 1980 la población de la ciudad de São Paulo creció más de seis veces, mientras la población del Gran São Paulo, fuera de la ciudad, creció dieciséis veces. ${ }^{5}$ Además, en la década de 1970, el crecimiento poblacional de las ciudades más alejadas del Gran São Paulo fue aún mayor que la de éste (Townroe y Keen, 1984). Tendencias similares se apreciaron desde hace varios años en el área metropolitana de la ciudad de México donde, durante la década de 1950, el crecimiento poblacional del área que rodea el Distrito Federal comenzó a experimentar mayores tasas de crecimiento que el área central. El porcentaje de la población y, por lo tanto, de la actividad industrial y comercial localizada dentro del Distrito Federal continuó disminuyendo (Unikel, 1970). Más aún, diversas ciudades vecinas del área metropolitana, aunque no dentro de ella, tuvieron una mayor tasa de crecimiento poblacional en la década de 1970 que el área metropolitana misma. Es también importante destacar que la tasa de crecimiento poblacional de Lima-Callao, entre 1972 y 1981, que en este último año tenía 4400000 habitantes, estaba entre las de menor ritmo de crecimiento al comparársela con otros centros urbanos del Perú con 50000 habitantes o más. ${ }^{6}$

Pero, con respecto a los cambios en la distribución de la población, es más ilustrativo analizar los flujos migratorios dentro de los países, pues éstos ponen en evidencia y ayudan a clarificar tendencias que las tasas de crecimiento de la población ocultan. Puede ser que los grandes centros metropolitanos de América Latina tengan tasas de crecimiento demográfico más bajas que muchas ciudades de menor tamaño, pero siguen siendo dominantes pues, por lo general, son los receptores de los mayores flu-

\footnotetext{
${ }^{4}$ Sin duda la disminución de la población en el Distrito Federal se debió, en parte, a la destrucción de Villas miseria realizadas por el anterior gobierno militar, lo que obligó a sus habitantes a trasladarse fuera del Distrito Federal.

${ }^{5}$ Extraído de estadísticas censales presentadas en un informe de 1985 sobre la ciudad de São Paulo, preparado por el Departamento de Planeamiento de la Municipalidad.

${ }^{6}$ Extraído de datos censales citados por Richardson, 1984, ob. cit.
} 
jos migratorios rurales y urbanos. Éste fue, sin duda, el caso de la ciudad de México durante las décadas de 1940 y 1950 , pues atrajo $49 \%$ de toda la migración nacional entre 1940 y 1950, lo que significó una cifr a nueve veces mayor que la recibida por Guadalajara, la ciudad que le siguió en cuanto a recepción de flujos migratorios. Entre 1950 y 1960, el flujo migratorio nacional que se dirigió a la ciudad de México descendió a 42\%, cifra que sólo triplicaba la migración hacia Guadalajara (Scott, 1982).

Es importante destacar que el modelo de desarrollo urbano de Cuba no se asemeja al de la mayoría de los países que experimentaron tasas de crecimiento económico similares durante las decádas de 1960 y 1970. A partir de mediados de la década de 1960, la población de La Habana, la ciudad más grande de Cuba, comenzó a disminuir. Una de las razones fue la reforma agraria, que al ser implementada poco después de la revolución de 1959, eliminó algunas de las causas principales de la migración rural a las ciudades. Desde entonces, los programas económicos y sociales promovidos en las áreas rurales y en otros centros urbanos, combinados con el sistema de racionamiento y con la postergación de nuevas inversiones en vivienda e infraestructura en La Habana, colaboraron a reducir la preponderancia económica y demográfica de esta ciudad sobre el sistema urbano nacional (Gugler, 1979).

\section{Asia}

El sur y el este de Asia ${ }^{7}$ tienen una menor concentración de población en ciudades de 100000 habitantes o más, o de 1 millón de habitantes o más, que África y América Latina. Sin embargo, tales estadísticas están inevitablemente influenciadas por la inclusión de China y la India que, juntas, representan más de los dos tercios de la población del Tercer Mundo asiático. Es interesante destacar las enormes diferencias que existen entre China y el resto del este de Asia (que incluye Hong Kong y Corea del Norte y del Sur), con respecto al nivel de concentración de la población en ciudades de 100000 habitantes o más, o de 1 millón de habitantes o más (cuadro 2). Hacia 1985, el Tercer Mundo asiático tenía cinco de los conglomerados urbanos más grandes del mundo: dos en China (Shanghai y Pekín), dos en la India (Calcuta y Bombay) y uno en Corea del Sur (Seúl). Cada uno de ellos tiene más de 10 millones de habitantes. ${ }^{8}$

\footnotetext{
${ }^{7}$ Nótese que Japón no está incluido en el análisis y tampoco en las estadísticas globales dentro del este asiático, sino entre los países desarrollados.

${ }^{8}$ Las cifras de la población de Shangai pueden utilizarse para ilustrar otro aspecto de lo difícil que es utilizar estadísticas urbanas en estudios comparativos, pero no contamos aquí con suficiente espacio para ahondar en el tema. Las cifras de Naciones Unidas indican que el conglomerado urbano de Shangai tiene más de 10 millones de habitantes e incluye a la municipalidad de Shangai y a 10 distritos vecinos con una superficie conjunta de más de 6000 kiló-
} 
Durante las décadas de 1960 y 1970 los países más ricos y con tasas de crecimiento económico más altas de Asia tenían, en general, el más alto porcentaje de sus poblaciones nacionales viviendo en centros urbanos. Entre 1960 y 1982, el porcentaje de la población nacional viviendo en "áreas urbanas" creció de 30 a $60 \%$ en Arabia Saudita, de 43 a $70 \%$ en Irak y de 28 a 61\% en Corea del Sur. En Arabia Saudita la inmigración jugó, sin duda, un importante papel en el crecimiento de la población urbana durante el mismo periodo, incrementado, quizás, por la presencia de trabajadores temporarios.

En cambio, durante el mismo periodo, los países más pobres y con un crecimiento económico relativamente bajo, tales como Bangladesh, Nepal, Birmania, la India y, en menor grado, Pakistán y Filipinas, experimentaron los menores crecimientos de población. Mientras que la producción industrial creció rápidamente durante esas décadas, como en Bangladesh y Pakistán, donde fue superior a $7 \%$ anual, hubo pocos cambios en la composición de la mano de obra dedicada a la agricultura.

Las tendencias urbanas en la India entre 1971 y 1981 ilustran cómo las estadísticas nacionales globales ofrecen una idea equívoca de lo que ocurre en países extensos y con una gran población. Entre las 12 ciudades con 1 millón de habitantes o más en 1981, Lucknow, Kanpur y Calcuta posiblemente experimentaron emigración poblacional, mientras que Bangalore crecía rápidamente (Harris, 1984). El análisis de las tasas de crecimiento poblacional (y de sus causas) de los centros urbanos con 20000 habitantes o más, en una región relativamente rica y urbanizada del sur de la India, no nos muestra una correlación clara entre el tamaño de los centros urbanos y sus tasas de crecimiento demográfico durante las últimas ocho décadas (Bhooshan, 1986).

Las ciudades de mayor crecimiento de la India durante la década de 1970 tenían menos de 500000 habitantes en 1971 y se caracterizaban por su especialización individual, o por ser centros de extracción de materias primas o capitales de estados. Muchas de ellas estaban alejadas de las áreas más densamente pobladas. Sin embargo, cerca de Bombay, Calcuta y Hyderabad, existen varias ciudades que crecieron más rápidamente que esos centros metropolitanos como, por ejemplo, Asansol y Durgapur, dos importantes ciudades industriales cerca de Calcuta, y Nasik Khopoli o la más

\footnotetext{
metr os cuadros. El área incluye extensiones agrícolas muy productivas y a numerosos pueblos y trabajadores agricolas. Hawkins, J. N., "Shangai: an explanatory report on food for a city" en suplemento del Geo. Journal, 1982. En las cifras de Naciones Unidas para la población de otros grandes conglomerados urbanos se utilizan límites más amplios que los recomendados por los investigadores; sin embargo, no se incluyen notas al pide de página que especifiquen los límites utilizados al determinar las cifras de población.
} 
alejada Aurangabad, cerca de Bombay. Éstas y otras ciudades de rápido crecimiento no son suburbios residenciales o industriales, aunque generalmente tienen poderosos vínculos económicos con los centros metropolitanos mencionados. Es posible que un "movimiento contrario a la polarización" esté comenzando en algunos centros urbanos de la India. Sin lugar a dudas, en varias áreas metropolitanas de la India el crecimiento poblacional durante la década de 1970 fue más rápido fuera de las ciudades centrales que en las ciudades mismas (Buch; Harris, 1984).

Las tendencias urbanas de China se destacan pues han tenido un rápido crecimiento económico y un rápido aumento de su producción industrial durante las décadas de 1960 y 1970, con pocas modificaciones en los porcentajes de población urbana. Richard Kirkby, en su estudio sobre la urbanización de China, sugiere que se comprenderían mejor tales tendencias si se considerara el desarrollo de China, después de la revolución de 1949, en tres periodos. El primer periodo comprende de 1949 a 1960 , cuando hubo un rápido crecimiento de la población urbana, en buena parte debido a la migración de la población rural a las ciudades. Durante esos once años se lanzan el Primer Plan Quinquenal y "el gran paso adelante". Si bien ambos planes tenían una visión muy diferente sobre la forma que debía adoptar el desarrollo de China, ambos compartían un mismo objetivo: el de acelerar el crecimiento industrial. El periodo 1961-1976 puede definirse, en cuanto a tendencias urbanas, como un periodo de "desurbanización". Esto se consiguió combinando reubicaciones forzadas masivas con un estricto control estatal en el acceso de la población al empleo, la vivienda y los alimentos. También se logró mantener un lento crecimiento de las ciudades reclutando campesinos para trabajar en la industria, pero sin permitirles que su núcleo familiar viviera con ellos en las ciudades, una costumbre ampliamente utilizada en décadas anteriores por los gobiernos colonialistas en los países de África al sur del Sáhara, para reducir el crecimiento urbano. El tercer periodo, entre 1976 y 1982, se destaca por el rápido crecimiento de la población urbana. Una vez más la migración rural a las ciudades fue el factor fundamental. Gran parte del crecimiento de la población urbana se debió al regreso a las ciudades, oficialmente aprobado, de muchos millones de habitantes que habían sido compulsivamente trasladados en años anteriores (Kirkby, 1985).

Es interesante destacar que un estudio de las tendencias recientes de los flujos migratorios hacia "regiones nucleares" en 46 países del Tercer Mundo, demostró que varias economías planificadas no tienen la habitual concentración de producción y población urbana que existe en la mayoría de los países con economía mixta o de mercado, por lo menos hasta 1980 (Vining, 1985). La "desurbanización" de China entre 1961 y 1976 y el caso de Cuba, en América Latina, ya han sido trätados. En Corea del Norte, el crecimiento de la población del área metropolitana de Pyongyang (la capital) ha sido también cuidadosamente controlado. 


\section{África}

África ha sido, desde hace mucho tiempo, el continente menos urbanizado del mundo a pesar de su variada aunque poco documentada y, a menudo, malinterpretada tradición urbana que se remonta a siglos atrás en muchos países y a milenios en algunos. Al igual que en otros continentes, existe una gran diversidad en los niveles de urbanización y en las tendencias del crecimiento urbano. Hacia 1985, según estimaciones de Naciones Unidas, ningún conglomerado urbano había llegado a los 10 millones de habitantes, aunque según otras fuentes, El Cairo tenía para entonces más de 10 millones de habitantes (Vining, 1985). El conglomerado urbano del área metropolitana de Lagos y sus alrededores era, hacia 1985, el segundo de África en cantidad de habitantes y, según algunos cálculos, vivían allí 5 millones de habitantes (Aradeon, Aira y Umo, 1986).

Si bien en 1980 la mayoría de los países africanos al sur del Sáhara tenían tres cuartas partes de su población asentada en áreas rurales y la mayor parte de su población económicamente activa estaba dedicada a tareas agrícolas, fue en esos países donde se produjeron los ejemplos más espectaculares de crecimiento de la población urbana durante las últimas cuatro décadas. Por ejemplo, la población de ciudades como Kartum (Sudán), Nairobi (Kenia), Abidján (Costa de Marfil) y Dar es-Salam (Tanzania), se multiplicó más de seis veces desde 1950, mientras que la población de Lagos (Nigeria) se multiplicó más de dieciséis veces (Hardoy, Satterthwaite, 1981). Algunos cálculos sugieren que la población de Nouakchott (Mauritania) se multiplicó cuarenta veces desde 1965 (Theunyck, y Dia, 1981). Se pueden dar otros ejemplos de rápidos incrementos de población en otras grandes ciudades al sur del Sáhara. En la mayoría de los casos los incrementos de población durante las décadas de 1950, 1960 y 1970 se debieron más a las migraciones internas que a los crecimientos vegetativos, a pesar de que entre los países de África se encuentren los que tienen la más alta tasa de crecimiento vegetativo del mundo.

Al menos, durante las décadas de 1960 y 1970 , el rápido aumento en los niveles de urbanización fue algo común para casi todos los países al sur del Sáhara, aunque sus niveles de producción aumentaron relativamente poco. En países como Chad, Zaire, la República Centroafricana y Ghana, por ejemplo, los indicadores económicos mostraron pocos cambios durante esas dos décadas. Aun así, el porcentaje de la población urbana cambió rápidamente entre 1960 y 1982: de 7 a 19\% en Chad, de 16 a $38 \%$ en Zaire, de 23 a $37 \%$ en la República de África Central, y de 23 a $37 \%$ en Ghana. Si estas cifras reflejan fielmente lo que sucedió en esos países, sería interesante compararlas con las de América Latina y Asia, donde es poco frecuente que países con pocos cambios en sus economías se urbanicen. 
En parte, la rápida urbanización de los países al sur del Sáhara se debe a que al momento de obtener su independencia política muchos de ellos tenían poca población urbana debido a las restricciones impuestas al crecimiento urbano por los poderes coloniales, las que fueron levantadas después de la independencia. Estos países carecían también de las estructuras institucionales necesarias en países independientes. Los factores más importantes que colaboraron a una mayor urbanización fueron la construcción de esta estructura institucional y los intentos, si bien fallidos, por reducir la dependencia en los productos manufacturados importados mediante un desarrollo industrial promovido por los gobiernos.

Tanzania es un buen ejemplo. En 1952, 27\% de los habitantes de la capital colonial, Dar es-Salam, no eran africanos y entre la población africana había 1.5 hombres por cada mujer. Una parte considerable de la migración rural a las áreas urbanas durante las décadas de 1950 y 1960 estuvo formada por mujeres con sus hijos que se desplazaban para reunirse con sus esposos. Bajo el régimen colonial, en décadas anteriores, fue vigorosamente desalentada la vida en común de las mujeres con sus esposos en los centros urbanos. Entre 1951 y 1967, un periodo de rápido crecimiento de la población urbana y con una migración rural neta hacia los centros urbanos mayor que su crecimiento vegetativo, las ciudades que crecieron más rápidamente fueron aquellas con un porcentaje de hombres mayor que el de mujeres. Las mujeres constituyeron el mayor porcentaje de migrantes, como lo demuestra la muy dispareja proporción de sexos en las áreas urbanas en 1967. Para entonces, en Dar-es-Salam había 1.2 hombres por cada mujer. En otros centros urbanos también se produjo un mayor equilibrio entre hombres y mujeres (Bryceson, 1983). Sospechamos que estos procesos, sumados a la consolidación institucional de los gobiernos, al entusiasmo generalizado de los gobiernos recientemente independizados por promover sustituciones a la importanción industrial y la baja prioridad otorgada a la agricultura, fueron los factores principales que contribuyeron a la rápida urbanización de muchos países al sur del Sáhara durante los últimos treinta años.

África del Sur se destaca como una excepción, ya que el rápido incremento de su PIB entre 1960 y 1982 se vio acompañado por pequeñas modificaciones en el porcentaje de la población urbana. África del Sur es el único país del Tercer Mundo con una economía de mercado o "mixta" que ha implementado políticas relativamente efectivas para controlar los flujos migratorios a las grandes ciudades. El sistema del apartheid, que niega a la mayoría de la población del país sus derechos económicos, políticos y sociales por motivos raciales, niega también el derecho de la población a moverse libremente cuando, simultáneamente, los obliga a migrar debido a la falta de empleos y a la pobreza en sus "tierras de origen", que son predominantemente rurales y hacia donde muchos de ellos fueron trasladados compulsivamente. 
En el norte de África la relación entre cambio económico y urbanización es más parecida a las que se observan en Asia y América Latina. Por ejemplo, entre 1970 y 1982, Argelia, Túnez, Libia y Marruecos tuvieron el mayor incremento del PIB y de la producción industrial de toda África; asimismo, tuvieron los mayores incrementos porcentuales de su población urbana.

La información disponible sobre las tasas de crecimiento de la población en ciudades de diferentes tamaños, o la distribución de la población en "regiones nucleares" es demasiado escasa como para sugerir tendencias generales para África. Las ciudades más grandes de cada país pueden llegar a atraer una menor proporción de las nuevas inversiones productivas. Quizá cause sorpresa descubrir que las dos ciudades más grandes de Kenia - Nairobi y Mombasa - tuvieron durante el último periodo intercensal, 1969-1979, una menor tasa de crecimiento de la población que cualquiera de los dieciséis centros urbanos con más de 20000 habitantes (Kiamba, Maingi, Ng'ethe y Senga, 1983). Recientes informes sugieren que el crecimiento poblacional de El Cairo ha disminuido considerablemente en años recientes (Vining, 1985). Hace poco se comprobó que la tasa de crecimiento poblacional de una ciudad cerca del área metropolitana de Lagos fue mayor que la de Lagos mismo (Aradeon, Aira y Umo, 1986) . Sin embargo, sería imprudente considerar esto como un indicador de tendencias hacia la descentralización del crecimiento urbano de las ciudades mayores de África.

\section{Centros urbanos pequeños y medianos}

Es interesante destacar el creciente interés de los gobiernos del Tercer Mundo, de las agencias internacionales y de los investigadores, por otros centros urbanos que no sean las ciudades y las áreas metropolitanas más importantes. A estos centros se los denomina, "pequeños y medianos" o "ciudades secundarias", aunque los criterios para definirlos sean tan variados como los utilizados para definir a los centros urbanos. Además, suele creerse que existen ciertas tendencias generales en las tasas de crecimiento poblacional de los centros urbanos pequeños o medianos de cierto rango en todo el Tercer Mundo. Por ejemplo, se dice que "las tasas de crecimiento poblacional de las ciudades dentro del rango de 20000 a 100000 habitantes han bajado sensiblemente desde 1950" (Mathur, 1982), o que "las ciudades medianas han crecido más lentamente que las ciudades en las categorías mayores o menores" (Rondinelli, 1982). Pareciera que se llegó a estas generalizaciones utilizando estimaciones de Naciones Unidas que demuestran que las poblaciones de los centros urbanos, dentro de cierta categoría de tamaño, crecen más lentamente que la población de las ciudades 
principales o grandes. ${ }^{9}$ Pero esta apreciación no fue confirmada al analizar los datos censales. El estudio de dos periodos intercensales de México, tres de Perú, tres de Tanzania, dos de Sudán y de seis a ocho periodos intercensales de dos regiones de la India y de una de Argentina no ofrece fundamento alguno para hacer las generalizaciones anteriores. En realidad, al menos para los centros urbanos de 20000 habitantes o más, el tamaño de su población al comienzo de un periodo intercensal no pareciera ser una guía confiable para determinar su tasa de crecimiento poblacional en relación con la de otros centros urbanos, hasta el siguiente censo. La base empírica utilizada para probar estas generalizaciones para el Tercer Mundo es muy reducida. Por eso sospechamos que las estadísticas intercensales de la mayoría de los países del Tercer Mundo con una población no inferior a algunos millones de habitantes, demostrarían que ciertos centros urbanos con poblaciones que oscilan entre 20000 y 200000 habitantes, crecieron más rápidamente que el centro urbano más grande del país y que otros crecieron más lentamente. Si se suma la población de los centros urbanos de cierto rango para dos censos y luego se extraen conclusiones generales sobre sus tasas de crecimiento, llegaremos a la conclusión de que tales generalizaciones tienen escasa validez ya que normalmente ocultan una considerable diversidad en las tasas de crecimiento poblacional entre los centros urbanos individuales de la misma categoría. En realidad, es más pertinente analizar la tasa de crecimiento poblacional de cada centro urbano en relación a las características sociales, económicas y hasta políticas propias de ese centro, que emitir conclusiones basándose únicamente en el crecimiento de su población.

Hay, quizá, dos aspectos particularmente importantes que subrayar en cuanto a las características de los centros urbanos de entre 20000 y 200000 habitantes de cualquier país o región. El primero es la gran diversidad que existe en la mezcla de factores (y su importancia relativa) que promovió su cambio poblacional. Un estudio de estos factores (Hardoy y Satterthwaite, 1986) mostró casos de centros urbanos en donde uno de los factores que se enumeran a continuación fue la causa principal de su crecimiento poblacional durante un reciente periodo intercensal: la localización de las sedes de gobiernos provinciales-estatales-regionales y de nuevos servicios públicos; vínculos multiplicadores con la producción agrícola; el alojamiento de la mano de obra para importantes obras públicas o el trabajo en la minería; su rol como centros de abastecimiento de importantes vías de transporte o como centros receptores de refugiados expulsados de sus lugares de origen por crisis sociales, inundaciones o sequías; el turismo nacional e internacional; su ubicación en el distrito electoral de poderosos políticos que las favorecen con inversiones públicas; su uso

\footnotetext{
${ }^{9}$ Rondinelli, D. A., ob. cit.
} 
permanente o semipermanente por jubilados y, finalmente, su elección como sedes de universidades o de cualquier otra institución de altos estudios. Todos estos factores se diferencian, en gran medida, de las acostumbradas explicaciones de que son las inversiones industriales las que impulsan el crecimiento de esos centros urbanos. Un segundo aspecto importante es la cantidad de centros urbanos pequeños con bajas tasas de crecimiento poblacional, característica que también rige para muchos centros urbanos grandes. Por ello, difícilmente puede sustentarse la teoría de que el crecimiento urbano es universal y rápido.

\section{Razones que sustentan el cambio urbano}

Para comprender el cambio urbano es necesario entender las fuerzas económicas, sociales, físicas y políticas más importantes que los sustentan. Si bien es cierto que durante mucho tiempo se reconoció que existen rasgos comunes entre los cambios urbanos de algunos países o grupos de países, también es cierto que se ha restado importancia a los rasgos que los diferencian, los que quizá sean más significativos.

Sin duda la mayor influencia sobre los cambios urbanos es la naturaleza de la base económica y laboral de cada país. En la mayoría de los países del Tercer Mundo con economías poco diversificadas los movimientos de la población se dan, básicamente, como respuesta a la localización de las oportunidades de empleo y, también de educación. En muchos países, los movimientos poblacionales se producen, en gran medida, como respuesta a una búsqueda de supervivencia. Esto contrasta con lo que sucede en los países industrializados de Europa Occidental y América del Norte, donde la elección individual y familiar del lugar donde se desea vivir, es cada vez más importante.

Los cambios económicos ejercen también una enorme influencia sobre la distribución del ingreso y, por lo tanto, sobre el nivel y distribución espacial de la demanda de bienes y servicios. Esto también ejerce una poderosa influencia sobre el cambio urbano. La desigual distribución de los ingresos en los países del Tercer Mundo se manifiesta en las ciudades en la calidad de las viviendas: la minoría vive en áreas residenciales de alto nivel y con buenos servicios, mientras que la mayoría lo hace en condiciones precarias, en diferentes tipos de alojamiento tales como casas de inquilinato, pensiones baratas, asentamientos ilegales y en viviendas autoconstruidas en subdivisiones ilegales.

La desigual distribución del ingreso o de los bienes es también evidente en los sistemas urbanos nacionales o regionales. Por ejemplo, el hecho de que muchas regiones de los países del Tercer Mundo sean predominantemente rurales y de que tengan bajos niveles de urbanización, refleja la falta de poder adquisitivo de la mayoría de los campesinos que suelen 
ser trabajadores sin tierra, mal pagados, o pequeños agricultores dentro de una economía de subsistencia. La falta de demanda de los bienes y servicios que normalmente proveen empresas localizadas en los centros urbanos se manifiesta en la ausencia de un desarrollo urbano en esas regiones. En cambio, en algunas regiones, el rápido incremento de la producción agrícola y una más equitativa distribución de la tenencia de la tierra fueron los principales factores que contribuyeron al rápido desarrollo urbano (Manzanal y Vapnarsky, 1986). La distribución más uniforme de los centros urbanos de diferentes tamaños sobre el territorio nacional de la mayoría de los países desarrollados refleja ingresos medios altos y una distribución más equitativa de los mismos.

Los cambios en la estructura política también ejercen una enorme influencia sobre los cambios urbanos, como ocurrió en los países que obtuvieron su independencia política o en las naciones con gobiernos comprometidos con una planificación central. Ya dimos algunos ejemplos de esto al referirnos a Tanzania y Cuba. Sin embargo, el papel que puede jugar un gobierno en promover el cambio urbano es muy variado. Quizá resulte -sorprendente comprobar que el lento crecimiento experimentado por muchas de las ciudades más grandes del mundo en décadas recientes, se deba muy poco a políticas gubernamentales expresamente diseñadas para reducir su crecimiento. En las economías centralmente planificadas las posibilidades del gobierno para influenciar el cambio urbano son, generalmente, más claras y explícitas. El deseo de reducir las diferencias regionales, en cuanto al desarrollo industrial, y razones de estrategia militar han influenciado poderosamente la localización de la inversión productiva. En China, por ejemplo, el disperso desarrollo industrial y diversas iniciativas para desarrollar el interior se vieron, en gran medida, influenciados por el deseo del gobierno, hasta hace pocos años, por reducir la concentración industrial de su vulnerable costa este (Kirkby, 1985). Por las mismas razones, el gobierno de Corea del Norte buscó reducir la concentración de las actividades productivas en las zonas cercanas a su frontera sur (Vining, 1985). Pero, aun en mercados o economías mixtas, las inversiones públicas en infraestructura y servicios, el gasto público y los incentivos o controles para alentar o desalentar inversiones en ciertas regiones o ciudades ejercen, sin duda, una importante influencia sobre el cambio urbano. Así como la inversión en defensa y en el programa espacial del gobierno de los Estados Unidos colaboró a apuntalar la redistribución de la población y de las actividades productivas hacia el sur y el oeste, también la inversión del gobierno federal de la India (y las inversiones en defensa realizadas décadas atrás por el antiguo gobierno colonial) colaboró a apuntalar el rápido desarrollo del centro metropolitano de Bangalore (Bhooshan, 1986). Corea del Sur, al igual que Corea del Norte, buscó también reducir la concentración de población y de la industria cerca de la frontera que divide ambos países. 
Sin embargo, puede ser más significativa, aunque sin duda no tan bien comprendida, la influencia que ejercen sobre los cambios urbanos las políticas macro-económicas de los gobiernos, el sistema impositivo, el régimen de fijación de precios de ciertos bienes de consumo y servicios y la distribución del poder y de los recursos entre los gobiernos nacionales, provinciales o estatales y locales (Hardoy y Satterthwaite, 1986). En muchos países del Tercer Mundo, las consecuencias espaciales de estas políticas alentaron una gran concentración de las actividades productivas en algunas ciudades o conurbaciones. Esto sucede cuando tales políticas favorecen, de forma explícita o implícita, el bienestar de los habitantes de los centros urbanos más grandes, y los intereses industriales, comerciales y financieros más poderosos que generalmente también se concentran en ellos. Calificar a esto de "favoritismo urbano" es incorrecto por dos razones. La primera es que los habitantes de bajos ingresos de los grandes centros urbanos, que generalmente constituyen la mitad o más de su población, raramente se benefician de tal favoritismo. Los servicios y el equipamiento de los grandes centros urbanos pueden parecer mejores tomados globalmente, pero no son siempre accesibles para los sectores de bajos ingresos. Un alto porcentaje de la población de la mayoría de las ciudades o áreas metropolitanas del Tercer Mundo se beneficia poco o nada de la concentración en ellas de inversiones públicas en infraestructura y servicios o de empleos bien remunerados. La segunda razón es el hecho de que la población de los centros urbanos pequeños y medianos está, normalmente, tan necesitada de inversiones públicas como la gran mayoría de la población rural (Hardoy y Satterthwaite, 1986).

Un conjunto fundamental de factores que influyen sobre las estructuras económicas y, por lo tanto, sobre los sistemas urbanos de todos los países, es el que se origina en el funcionamiento de los mercados mundiales. Todos los países se vieron afectados por la transformación sin precedentes de la economía y de la estructura política mundial a lo largo de los últimos ciento cincuenta años, aproximadamente. El papel diferente que jugaron en el mercado mundial algunas empresas fue tan fundamental para el rápido crecimiento de la población de São Paulo y Seúl y de sus alrededores en décadas recientes, como lo fue para el rápido incremento de la población de Londres durante gran parte del siglo XIX y para su declinación, a partir de la década de 1940. Sólo algunos gobiernos independizaron sus economías de las fuerzas del mercado mundial: por ejemplo China, durante gran parte de las décadas de 1950, 1960 y comienzos de la década de 1970; Birmania, en décadas recientes, entre otros casos. Grupos o bloques de países también intentaron hacerlo como, por ejemplo, el COMECON, especialmente durante la década de 1950, y también, en Occidente, la Comisión Económica Europea al fijar su política agrícola. Pero ninguna economía es totalmente impermeable. Además, debido al endeudamiento externo que enfrentan muchos países del Tercer Mundo, 
los cambios en el gasto público y en la orientación de las inversiones sociales que muchos gobiernos se ven forzados a realizar, tendrán un impacto crítico sobre el cambio urbano. Igualmente importante es la constante tendencia hacia el proteccionismo de las economías del mundo desarrollado. La estructura económica y la tasa de crecimiento poblacional de una ciudad del Tercer Mundo cuya economía se desarrolló en base a ciertas exportaciones, se verían considerablemente afectadas si, de pronto, se impusieran restricciones a la venta de sus productos en el mercado exterior. La disminución de la ayuda multilateral con fondos reembolsables puede también inhibir la construcción o el mejoramiento de la infraestructura necesaria para promover el desarrollo urbano en muchos países del Tercer Mundo. Estos son sólo algunos ejemplos que demuestran la complejidad que significa identificar los factores que promueven el cambio urbano en cualquier país o región y descubrir su importancia relativa. Sin duda, esta mezcla de factores y su importancia relativa cambian con el tiempo.

\section{¿Cuál es el futuro urbano?}

Esta breve reseña sobre algunos de los factores que influyen sobre los cambios urbanos en el Tercer Mundo nos brinda el contexto para evaluar la validez de las proyecciones de Naciones Unidas para los futuros niveles de urbanización por países o de las futuras poblaciones de ciertas ciudades del Tercer Mundo. Estas proyecciones se basan, esencialmente, en la extrapolación de las tendencias del crecimiento de la población del pasado, pero pueden resultar una mala guía para estimár futuros desarrollos. Como lo intentamos demostrar, los cambios poblacionales en cualquier ciudad o los cambios en los niveles de urbanización de cualquier país, se ven influenciados por factores económicos, sociales y políticos que no pueden predecirse con certeza para el año 2000, y menos para el 2025, como aparecen en las últimas proyecciones de Naciones Unidas (Naciones Unidas, 1982 y 1985).

Si extrapolamos las tendencias del crecimiento de la población urbana de China, desde 1949 hasta 1960, para tener una ídea de lo que sucederá en ese país en los siguientes cuarenta años, descubriremos que la población de China sería $100 \%$ urbana antes del año 2000. Difícilmente serviría tal proyección como un indicador de las tendencias futuras después de 1969, pues la población urbana de China disminuyó porcentualmente entre 1961 y 1976 (Kirkby, 1985). Si se extrapolara el crecimiento poblacional de São Paulo, de sus 48000 habitantes en 1886 a los 484000 habitantes en 1916, nos daría una población de 48 millones aproximadamente en 1976 (Loreto y Hardoy, 1984). Estos ejemplos pueden parecer demasiado extremos para cuestionar el valor de las proyecciones futuras, 
pero también nos parecen poco reales las proyecciones de Naciones Unidas para ciudades como Dar es-Salam (Tanzania), Nairobi (Kenia) y para varias ciudades de Nigeria. Hasta para una persona con escasos conocimientos sobre la economía de Tanzania y del potencial de su desarrollo urbano, resultaría difícil imaginar los cambios económicos que tendrían que ocurrir para apoyar un conglomerado de 4.8 millones de personas en Dar es-Salam dentro de quince años (Naciones Unidas, 1980). La pregunta obvia es: ¿en dónde vivirán y de qué se alimentarán? La gente no se trasladará a Dar es-Salam si no tiene posibilidad de encontrar un ingreso o de alimentarse. Por razones similares, la sugerencia de que Nairobi, en Kenia, crecerá de menos de 1 millón de habitantes a 18.9 millones entre 1980 y el año 2025, según las proyecciones de Naciones Unidas, debe tomarse con muchas dudas. Esto significaría que, en menos de cuarenta años, Nairobi tendrá una población tres veces mayor que la que actualmente vive en el área metropolitana de Londres.

Además, es difícil creer que se puedan hacer proyecciones para dentro de cuarenta años, de ciudades que no cuentan con datos poblacionales confiables desde hace más de veinte años. Por ejemplo, con toda tranquilidad aparecen proyecciones sobre la población de algunas ciudades de Nigeria, como Lagos y Ado Ekiti, para el año 2025, cuando no existen datos censales confiables desde 1963. Incluso, Ado Ekiti, una ciudad nigeriana relativamente desconocida (y poco importante), aparece en las proyecciones para el 2025 como el vigésimo quinto conglomerado urbano del mundo, con 15.4 millones de habitantes. La fundamentación de tales proyecciones, las que suponen un crecimiento constante de la población de las áreas urbanas, se basa en que todos los países del Tercer Mundo experimentarán transformaciones económicas similares a las experimentadas por los países industrializados de Europa y América del Norte. Esto resulta algo desconcertante, pues muy pocos expertos en desarrollo apoyarían seriamente la idea, tan popular en las décadas de 1950 y 1960, de que existe un desarrollo histórico lineal por el cual han de pasar todos los países del mundo.

Existe un fuerte paralelismo entre las técnicas que se emplean para pronosticar las futuras poblaciones de las ciudades y las utilizadas, a comienzos de la década de 1970, para pronosticar la demanda de energía. En aquel entonces se suponía que la demanda de energía de Occidente seguiría incrementándose siguiendo las tendencias anteriores, lo mismo que se supone que las tendencias urbanas del pasado inmediato continuarán siendo el modelo de los cambios urbanos futuros. La crisis provocada por el alza del precio del petróleo en 1973 hizo que se redujeran un poco los pronósticos sobre la demanda de energía, pero no se introdujeron modificaciones importantes en la metodología para hacer estos pronósticos. Quizás, debido a la recesión, se estén reduciendo ahora las proyecciones de hace 5 o 10 años atrás sobre el crecimiento urbano del Tercer Mundo. 
Sucesivos informes de Naciones Unidas durante los últimos diez años han ido reduciendo las cifras de las proyecciones poblacionales para el año 2000 de ciudades como Río de Janeiro, Bombay y la ciudad de México.

Luego de rigurosos estudios de los cambios económicos y sociales que impulsaron un cambio en la demanda de energía a mediados de la década de 1970 (Leach, Lewis, Romig, Van Buren y Foley, 1979), se reconoció que las tendencias del pasado inmediato constituyen un modelo poco confiable para el futuro. La proyección de las tendencias del pasado, aun cuando sean parcialmente actualizadas, no tienen en cuenta los cambios económicos y sociales que causaron los cambios en la demanda de energía. En la mayoría de los países de Occidente hay un bajo crecimiento poblacional, poco incremento en la cantidad de núcleos familiares, una reducción en la importancia otorgada a industrias con alto consumo energético y una creciente importancia de las actividades económicas de bajo consumo energético por unidad de valor agregado. Sin lugar a dudas, estos factores tienen fundamental incidencia en la forma en que cambia la demanda de energía. Si se pretende hacer proyecciones realistas sobre la población de las ciudades del Tercer Mundo, tales proyecciones deberán también basarse en análisis similares sobre los cambios sociales y económicos.

Los expertos que analizan el cambio urbano en Occidente tienen poderosas razones para declarar que allí existen tendencias y factores similares que promueven tales tendencias. Diversos censos recientes realizados en varios países o regiones de Occidente sugieren que al cambio urbano actual se le podría denominar "desurbanización", es decir, todo lo contrario de la constante progresión hacia la "megalópolis", que era el "futuro urbano" pronosticado hace sólo diez años. El hecho de que existen tendencias similares en muchos países o regiones de Occidente, en cuanto a la redistribución de la población a nivel regional entre centros metropolitanos, y entre centros metropolitanos, centros no metropolitanos y áreas rurales, nos brinda un panorama más amplio para el estudio de los factores comunes que subyacen en tales tendencias. De ciertas regiones pobres del Tercer Mundo también se podría decir que estarían comenzando un proceso de "desurbanización". Sin embargo, es imposible comparar ambos procesos. Es probable que en las regiones pobres del Tercer Mundo la gente migre de la ciudad al campo para asegurarse los alimentos necesarios para su subsistencia. En cambio, en los países desarrollados, la "desurbanización" refleja la capacidad de la gente para vivir o trabajar en áreas rurales, aunçme manteniendo formas de vida más urbanas que rurales debido, en gran medida, a los enormes progresos del transporte, de la tecnología de las comunicaciones y a mayores ingresos.

Un eminente experto en urbanismo sugirió una alternativa al futuro urbano dominado por las grandes ciudades. Propuso la existencia de un modelo general de crecimiento y cambio urbano que se puede aplicar a todos los países, pues sus sistemas urbanos van desde los dominados por 
una ciudad principal, pasando por la descentralización del desarrollo urbano fuera de las ciudades centrales a los anillos suburbanos y, finalmente, hasta el desarrollo urbano concentrado en áreas no metropolitanas (Hall, 1983). Por lo tanto, con el tiempo, los países o regiones del Tercer Mundo llegarían también a la "desurbanización". Esto más o menos sugiere que los gobiernos del Tercer Mundo no deberían preocuparse por el crecimiento de sus grandes ciudades pues, con el tiempo, el desarrollo urbano tenderá a descentralizarse. Este modelo se apoya, en cierta medida, en los últimos cambios verificados en algunos de los más grandes centros urbanos del Tercer Mundo, o cerca de ellos, como se describiera anteriormente.

Pero este modelo también supone que el cambio económico en todos los países del Tercer Mundo será similar al que actualmente está ocurriendo en Europa Occidental y América del Norte. Los cambios económicos son los que normalmente tienen mayor influencia sobre los cambios urbanos pero, además, influyen sobre los cambios sociales los que, a su vez, inciden en los cambios urbanos. Sin embargo, existen dos razones que demuestran que esta visión futurística es tan improbable como la de Naciones Unidas. La primera es la enorme diversidad existente en el Tercer Mundo; un modelo común de cambios urbanos parece tan poco probable como un modelo común de cambio económico. La segunda es que hay muchos países del Tercer Mundo sin ninguna posibilidad de alcanzar economías prósperas y estables, salvo que el sistema económico mundial se modifique significativamente. En tal situación, no tienen posibilidades de desarrollar un modelo urbano que dependa de grandes inversiones de capital, de cambios económicos importantes y de un nivel de prosperidad aceptable. Además, la mayoría de sus ciudadanos no podrían darse el lujo de elegir dónde desean vivir, si no es en función de una constante búsqueda de los ingresos que necesitan para sustentarse.

\section{Bibliografía}

Aradeon, D., T. Aina y J. Umo, "South-West Nigeria", en Small and intermediate urban centres. Their role in national and regional development in the Third World, Jorge E. Hardoy y David Satterthwaite (editores), Hodder and Stoughton, Londres, 1986.

Bryceson, D., Urbanization and agrarian development in Tanzania with special reference to secondary cities, documento interno del IIED, Londres, 1983.

Buch, M. N., Urbanization trends in India: the emerging regional patterns, trabajo mimeografiado.

Di Loreto M., y J. E. Hardoy, "Procesos de urbanización en América Latina", Boletín de Medio Ambiente y Urbanización, año 3, núm. 9, Buenos Aires, 1984.

Gugler, J., "A minimum of urbanism and a maximum of ruralism: the Cuban experience", international Journal of Urban and Regional Research, vol. 4, 1980, pp. 516-535, y Jorge E. Hardoy, Urban and agrarian reform in Cuba, SIAP-IDRC, Ediciones SIAP, Buenos Aires, 1979. 
Hall, P., "Cities as dinossaurs: the end of the urban age?", documento presentado en la Conferencia Anual del Instituto Real de Planeamiento Urbano, 1983.

Hardoy, J. E. y D. Satterthwaite, "A survey of empirical material on the factors affecting the development of small and intermediate urban centres" (capitulo 7), en Small and intermediate urban centres, 1986.

y D. Satterthwaite, Shelter: need and response. Houssing, land and settlement policies in seventeen Third World nations, John Wiley and Sons, Chichester, Inglaterra, 1981

Harris, N., "Some trends in the evolution of big cities", Habitat International, vol. 8, núm. 1, 1984.

Kiamba, C. M., K. Maingi, N. Ng'ethe y W. M. Senga, "The role of small and intermediate cities in national development: the case study of Thika, Kenya". Documento presentado en un Seminario International sobre Ciudades Pequeñas y Desarrollo Urbano. Delhi, enero de 1983.

Kirkby, R. J. R., Urbanization in China: town and country in a developing economy, 1949-2000, Croom Helm, Londres, 1985.

Leach, G., C. Lewis, F. Roming, A. van Buren y G. Foley, "A low energy strategy for the United Kingdom", Science Reviews, 1979, y documentos anteriores preparatorios para este trabajo.

Manzanal, Mabel y César Vapnarsky, "El desarrollo del Alto Valle de Río Negro y Neuquén, en la Región de Comahue, Argentina", en Hardoy y Satterthwaite, editores, Small and intermediate urban centres,1986.

Mathu, O. P., "The role of small cities in national development", en Small cities and national development, UNCRD, Nagoya, 1982.

Naciones Unidas, Estimates and proyections of urban, rural and city populations, 1950-2025: the 1982 assessment. ST/ESA/SER.R/58, Nueva York, 1985. , Urban, rural and city population, 1950-2000, as assessed in 1978, Nueva York, junio, 1980.

, Patterns of urban and rural population growth, Estudios sobre Población núm. 68, ST/ESA/SER.A/68, 1980.

Rofman, Alejandro B., "Argentina: un modelo maduro de urbanización", Cities, vol. 2 , núm. 1, febrero de 1985.

Rondinelli, D. A., "Intermediate cities in developing countries", Third World Planning Review, vol. 4, núm. 4, noviembre de 1982.

Scott, I., Urban and spatial development in Mexico, Johns Hopkins University Press, Baltimore y Londres, 1982.

Theunyck, S. y M. Dia, "Young (and less young) in infra-urban ENDA, Dakar, 1981, pp. 206-233.

Townroe P. M. y D. Keen, "Polarization reversal in the state of São Paulo, Brazil", Regional Studies, vol. 18.1, 1984, pp. 45-54.

Unikel, L., en "The dynamics of the growth of Mexico City", trabajo mimeografiado (1970), publicado en español por la Fundación para Estudios de la Población, A.C., México, 1972.

Vining, D. R. Jr., "The growth of core regions in the Third World", Scientific American, vol. 252, núm. 4, abril de 1985. 